ARCHIVO ESPAÑOL DE ARTE, XC, 358

ABRIL-JUNIO 2017, pp. 183-190

ISSN: 0004-0428, eISSN: 1988-8511

doi: $10.3989 /$ aearte.2017.12

\title{
VARIA
}

\section{NUEVAS APROXIMACIONES EN TORNO A LA MAIESTAS DE LA BIBLIA DE 1162 DE SAN ISIDORO DE LEÓN EN EL MUSEO ARQUEOLÓGICO NACIONAL}

(MADRID)

\author{
ANA HERNÁNDEZ ${ }^{1}$ \\ Universidad Complutense de Madrid
}

En el MAN se conserva un folio suelto con una Maiestas a toda página que ha sido atribuido a la Biblia de 1162 de San Isidoro de León por Joaquín Yarza. El análisis comparativo de ambas piezas y la consulta de documentación permiten confirmar esta identificación y profundizar en el conocimiento de las obras.

Palabras clave: miniatura románica; Biblia; Maiestas; Museo Arqueológico Nacional; Real Colegiata de San Isidoro de León; Ricardo Velázquez Bosco.

\section{THE MAIESTAS OF THE 1162 BIBLE OF SAN ISIDORO DE LEÓN IN THE MUSEO ARQUEOLÓGICO NACIONAL (MADRID)}

Joaquin Yarza has attributed a loose folio containing a full-page representation of the Maiestas in the MAN to the 1162 Bible of San Isidoro de León. A comparative analysis of both works and documentary evidence confirm this identification, thereby deepening our understanding of the works.

Key words: Romanesque miniature; Bible; Maiestas; Museo Arqueológico Nacional; Real Colegiata de San Isidoro de León; Ricardo Velázquez Bosco.

Cómo citar este artículo / Citation: Hernández, Ana (2017): "Nuevas aproximaciones en torno a la Maiestas de la Biblia de 1162 de San Isidoro de León en el Museo Arqueológico Nacional (Madrid)". En: Archivo Español de Arte, vol. 90, núm. 358, Madrid, pp. 183-190. doi: 10.3989/aearte.2017.12

La Real Colegiata de San Isidoro de León custodia dos Biblias entre las que existe indudablemente una relación de modelo-copia. La más antigua de ellas fue producida en el año 960 en el desaparecido monasterio de Valeránica (Burgos) por el escriba Florencio y su discípulo Sancho $^{2}$. Se trata de un volumen que contiene el texto de la Vulgata completo extensamente ilustrado en sus 514 folios y que se encontraba en la institución leonesa al menos desde mediados del

1 aherna05@ucm.es / ORCID iD: http://orcid.org/0000-0002-9566-1412.

2 Archivo de la Real Colegiata de San Isidoro de León, León (ASIL), Códice II. En torno al cenobio de Valeránica: Williams, 1970: 231-248; Pérez de Urbel, 1975: 71-89; Shailor, 1975; Díaz y Díaz, 1999: 53-72; García Molinos, 2004 : 241-430. El análisis más completo sobre este manuscrito es la colección de estudios que acompaña a su facsímil: Martínez/Sábugo Pintor/Del Valle Menéndez/Viñayo González, 1999. Ver también: Suárez González (2013). 


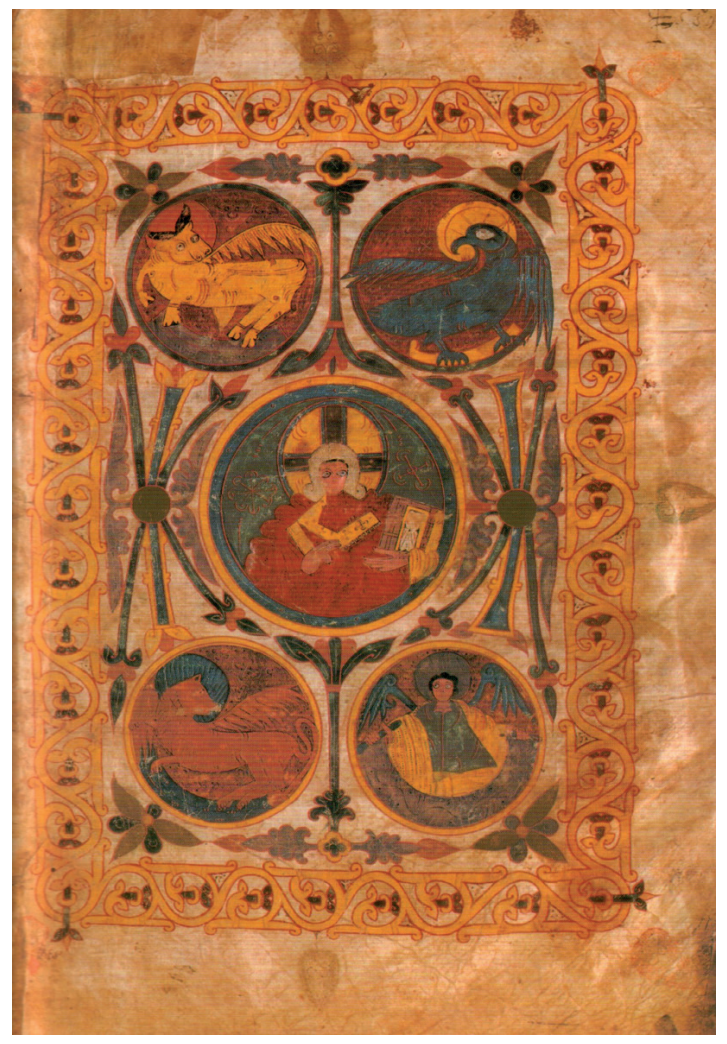

Fig. 1. Maiestas. Archivo de la Real Colegiata de San Isidoro de León, Códice II, f. 2r. Fotografía de la autora a partir del facsímil.

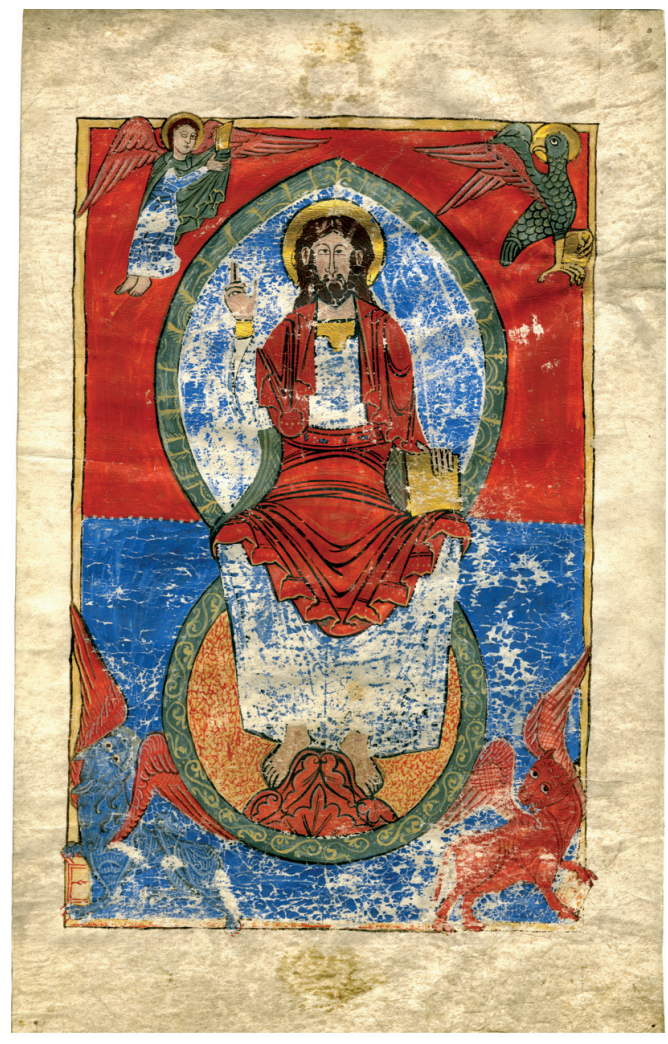

Fig. 2. Maiestas. Museo Arqueológico Nacional, número de inventario 52455. Reproducido con el permiso del MAN. Fotografía del MAN.

siglo XII. Allí fue empleada como prototipo para un nuevo manuscrito rematado en el año 1162 y promovido por el abad de la recientemente trasladada comunidad de canónigos, Menendo 3 . Dividido en tres tomos de gran tamaño, cuenta con unas dimensiones medias de 527-556 $\times 361$ $374 \mathrm{~mm}$. y 615 folios $^{4}$. También ampliamente iluminado, su programa decorativo sigue las pautas marcadas por su modelo del que se desvía en pocas ocasiones, más allá de la actualización de su estilo acorde con el cambio estético producido en los dos siglos que los separan ${ }^{5}$.

La Biblia del año 960 abre, tras las guardas, con una representación a toda página de Cristo en majestad rodeado del tetramorfos (fig. 1). Su iconografía ha sido relacionada con imágenes semejantes en evangeliarios fundamentalmente carolingios por John Williams, quien dedicó su tesis doctoral a este códice ${ }^{6}$. El ejemplar de 1162, sin embargo, no contiene actualmente Maiestas alguna pese a incluir los mismos pasajes ilustrados, frontispicios iluminados y esquemas figurados que su prototipo del siglo X. Joaquín Yarza resolvió el enigma de esta falta en 1985 al atribuir un folio descontextualizado (fig. 2) conservado en el Museo Arqueológico Nacional de Madrid (MAN) al volumen leonés. En sus propias palabras:

\footnotetext{
3 ASIL, Códice III. Para un exhaustivo análisis paleográfico y codicológico de esta obra: Suárez González, 1997.

4 Suárez González, 1997: 108-110. Según esta autora, existen indicios de que la Biblia de 1162 ha perdido al menos cinco folios originales.

5 Suárez González, 1997: 91. Esta investigadora ha advertido cómo el manuscrito del año 960 fue desencuadernado en el siglo XII, reafirmando la idea de que la Biblia de 1162 se produjo como una copia directa del códice altomedieval procedente de Valeránica.

${ }^{6}$ Williams, 1962: 43-47.
} 


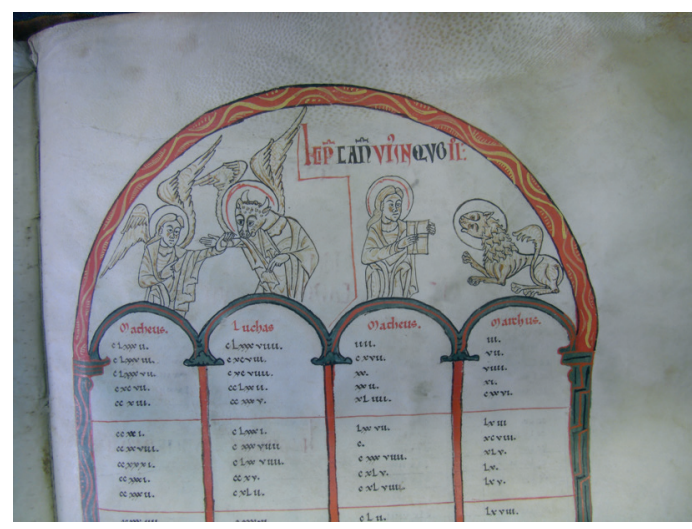

Fig. 3. León, Archivo de la Real Colegiata de San Isidoro de León, Códice III.3, f. 67r (detalle). Reproducido con el permiso de la Real Colegiata de San Isidoro de León.

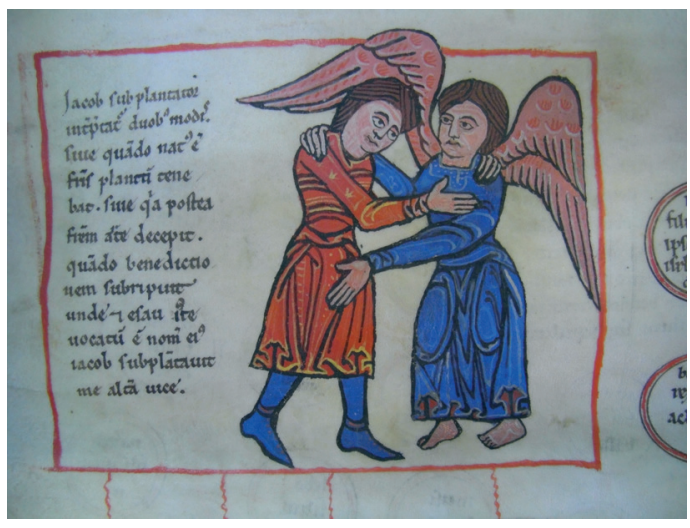

Fig. 4. León, Archivo de la Real Colegiata de San Isidoro de León, Códice III.1, f. 4v (detalle). Reproducido con el permiso de la Real Colegiata de San Isidoro de León.

En el Museo Arqueológico Nacional de Madrid se guarda un folio de grandes dimensiones con una "Maiestas", de incierta procedencia, cuyo estilo coincide muy estrechamente con el de la Biblia leonesa. Mide 35,8 × $23 \mathrm{cms}$, mientras la Biblia llega a 38,5 × 30,5 cms. Es más cuidada la ejecución que la mayoría de las miniaturas del manuscrito tan apresuradamente realizadas [...] En la Biblia leonesa falta la "Maiestas" que, sin embargo, está en el ejemplar de 960 realizado según el mismo modelo (fol. 1). Sugiero, en consecuencia, que se considere la posibilidad de que el folio suelto del museo de Madrid, llegado allí a través de desconocidos avatares, proceda de la Biblia leonesa de San Isidoro de León (1162) ${ }^{7}$.

La percepción de Yarza es acertada, este folio perteneció casi con total seguridad a la Biblia románica isidoriana como se verá a continuación. Ello pese a las discrepancias de tamaño entre el códice y esta pieza $(456-457 \times 281-287)^{8}$, que se deben a que ha sido recortada como ha señalado Ángela Franco 9 .

Las extraordinarias concomitancias estilísticas entre ambas obras apuntan indudablemente a esta filiación. No hay más que comparar fórmulas empleadas en la imagen como la posición y construcción de los animales que ocupan las esquinas inferiores del folio con aquellas que aparecen en las tablas de cánones de la Biblia (fig. 3). Estas semejanzas no se limitan a su aspecto general, sino que se advierten en las pautas utilizadas para conformar detalles menudos como patas, colas y rostros, o el característico escorzo que realizan las cabezas de buey y león hacia arriba. Así, se revelan paralelos con la Biblia en prácticamente todas las particularidades de la Maiestas descontextualizada, desde el modo en el que se han plasmado las alas del tetramorfos (fig. 4), las plumas y garras del águila, o el pelaje de buey y león, hasta las facciones de los personajes y la manera en la que se dibujan los pliegues de sus ropajes (fig. 5).

7 Yarza Luaces, 1985: 386-387; 1990: 21 (n. 133); 1994: 278-280. El folio se encuentra en el MAN, n. ${ }^{\circ}$ inventario 52455. Cabe señalar asimismo que, tras la propuesta de Yarza de atribución de este folio a la Biblia de San Isidoro de León y la aceptación de la misma por parte de otros investigadores como Ángela Franco (Franco Mata, 1988: 40; 2010: 102-104), se desmentía su adscripción al Beato de Cardeña (MAN, n. ${ }^{\circ}$ inventario 1962/73/2) propuesta por: Mundó/ Sánchez Mariana, 1976: 36-38.

${ }^{8}$ En el catálogo online del MAN (http://ceres.mcu.es/pages/Main), las dimensiones del folio se fijan en $446 \times 286 \mathrm{~mm}$.

9 Franco Mata, 1988: 40; 2010: 102-104. Quizá la referencia más fiable a la que acudir para comparar las dimensiones del folio del Arqueológico con las de la Biblia isidoriana, dado el recorte sufrido por el primero, es la superficie que ocupa la propia imagen del Cristo en majestad. Esta se inserta en un marco rectangular de $355 \times 229$ mm acercándose, por tanto, aunque con una magnitud ligeramente inferior, a otras ilustraciones a toda página en la Biblia de 1162. Por ejemplo, las tablas de cánones miden unos 380-395 × 240-260 mm. 


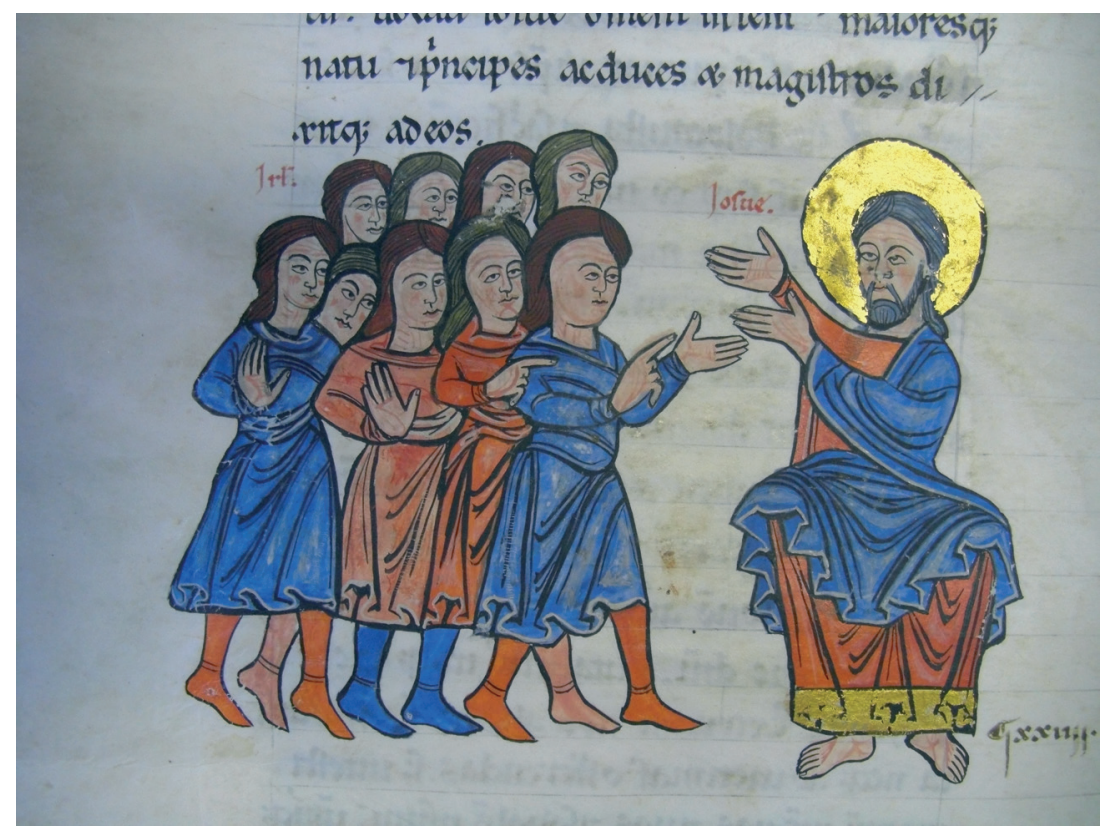

Fig. 5. León, Archivo de la Real Colegiata de San Isidoro de León, Códice III.1, f. 101v (detalle). Reproducido con el permiso de la Real Colegiata de San Isidoro de León.

Las mismas soluciones se muestran en la representación estilísticamente más cercana al folio que, sorprendentemente, ocurre a cientos de kilómetros de León: el pantocrátor de la bóveda de la cripta norte de San Vicente de Roda de Isábena en Huesca (fig. 6). Ambas imágenes cuentan con patrones compositivos y estéticos gemelos, salvando aquellas diferencias debidas a la disparidad de soportes, que se observan, por ejemplo, en el grueso delineado negro o la solución de los pliegues. En el caso de la figura central, son parejos el modo en el que la mano se alza en signo de bendición y cómo la manga de la túnica muestra la prenda interior, la manera en la que el manto cae sobre los hombros y el regazo de Cristo, o la disposición del libro sobre su rodilla izquierda, levantando el pulgar de la mano que lo sujeta. También en el tetramorfos (fig. 7) se perciben llamativas analogías: la formulación de las alas con una doble fila de plumas, sus posturas, el ademán con el que sostienen los evangelios —en Mateo incluso se repiten las manos veladas-, o la decoración en forma de escamas sobre el cuerpo del águila con una doble línea que antecede a la cola.

Los paralelos entre el aparato gráfico de la Biblia de 1162 y las pinturas de Roda no se limitan a la Maiestas, sino que se evidencian en general en los manierismos que muestra uno de los cuatro miniaturistas que trabajaron en las ilustraciones del manuscrito, autor también del folio. Las fórmulas que este pintor emplea son tan afines a aquellas de los frescos que es muy posible que nos hallemos ante una misma mano trabajando en territorio oscense y leonés, capaz de obrar en soportes tan diversos como el pergamino y el muro ${ }^{10}$.

En cuanto a la relación del Cristo en majestad del folio con aquel de la Biblia del año 960, cabe señalar que el primero incluye numerosas diparidades iconográficas con respecto a la segunda. Es esta una eventualidad infrecuente dentro del ciclo ilustrado del manuscrito del si-

${ }^{10}$ La vinculación entre las pinturas de Roda de Isábena y la Biblia de 1162 ha sido sugerida por otros autores, aunque siempre a través del vínculo de ambas obras con los murales de Navasa (Huesca). Estos, si bien están relacionados con el estilo del manuscrito leonés, probablemente no se deban a la misma mano como sí ocurre con aquellos de la Ribagorça. Yarza Luaces, 1985: 386; Castiñeiras González, 1996: 96-97. He profundizado en los paralelos entre las pintura de Roda y el manuscrito leonés en mi tesis doctoral: Tradición y copia en la ilustración de manuscritos bíblicos en la península ibérica. Las Biblias de San Isidoro de León y San Millán de la Cogolla (Universidad Complutense de Madrid, 2016). 
glo XII cuyo ciclo de miniaturas, fundamentalmente veterotestamentarias, suelen seguir casi al pie de la letra las pautas compositivas del original de Valeránica. El alejamiento, en este caso, se ha debido probablemente a que la Maiestas era una imagen tan familiar para los miniaturistas de la duodécima centuria que se dejaron guiar por las soluciones empleadas en el momento para este tipo de escenas, sin necesidad de recurrir al prototipo iluminado. De este modo, se han sustituido los medallones que enmarcan las figuras en el ejemplar altomedieval por un fondo liso dividido horizontalmente en dos colores, rojo y azul, y una mandorla doble en el centro que cobija la figura de Cristo, ahora barbado y de cuerpo completo $^{11}$. Tampoco se ha imitado el orden en el que se disponen los símbolos de los evangelistas, de tal manera que en el ejemplar más tardío se organizan como suele ocurrir en el arte occidental desde época carolingia, a diferencia de su modelo que sigue posiblemente una fuente precarolina ${ }^{12}$.

La representación resultante continúa los patrones habituales de este tipo de escenas en época plenomedieval ${ }^{13}$. Dentro del propio San Isidoro de León contamos con varios ejemplos, el más evidente el pantocrátor de la bóveda del Panteón Real, aunque las diferencias iconográficas que lo distancian del folio son tan amplias que no se puede considerar que los miniaturistas se hubiesen inspirado en este mural ${ }^{14}$. La disposición de la figura central de la miniatura del MAN recuerda, sin embargo, a la del relicario del museo de la colegiata leonesa, el denominado "portapaz", en especial la disposición de sus manos, el modo en el que cuelgan los ropajes, la ornamentación del cuello de la túnica, y la decoración de la mandorla cuyo borde en el folio parece evocar una filigrana de orfebrería similar a la que cubre parte del fondo de la pieza de marfil ${ }^{15}$.

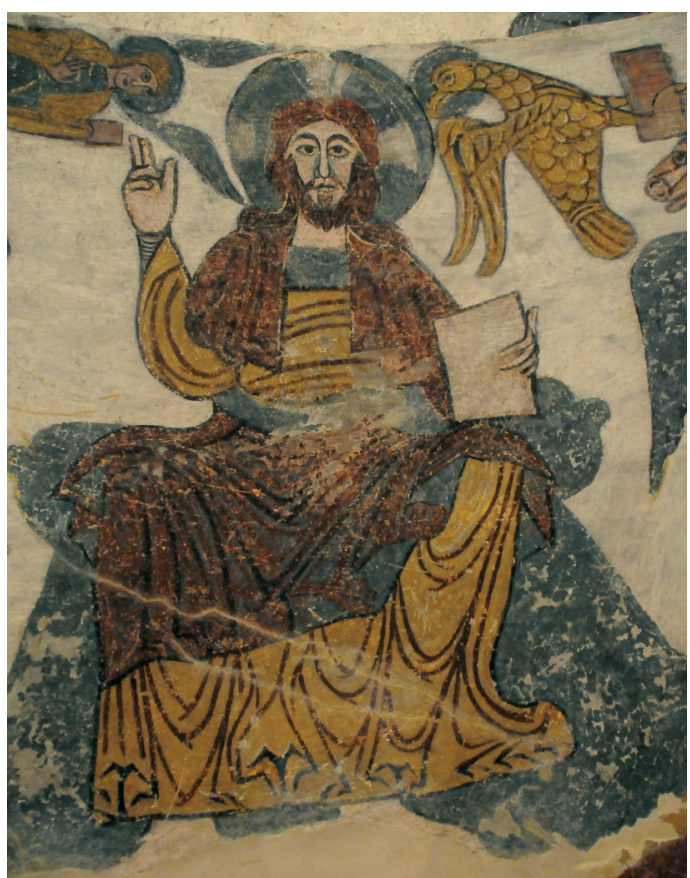

Fig. 6. Pintura mural de la cripta norte de la catedral de Roda de Isábena (detalle). Fotografía de la Dra Immaculada Lorés. Reproducida con su permiso.

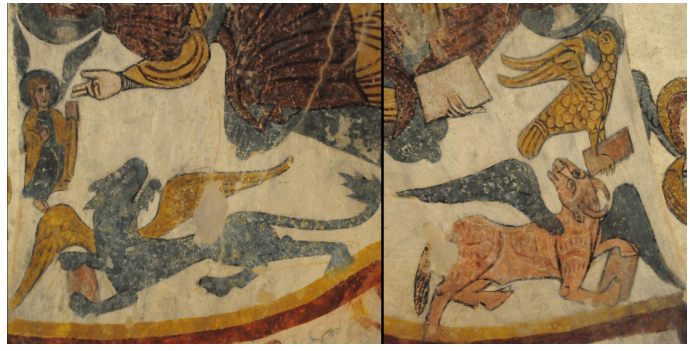

Fig. 7. Pintura mural de la cripta norte de la catedral de Roda de Isábena (detalles). Fotografía de la Dra Immaculada Lorés. Reproducida con su permiso.

11 Williams, 1962: 44-45.

12 Williams, 1962: 46-47.

13 Existen múltiples instancias semejantes de este tipo de representaciones a lo largo de todo el territorio europeo. Algunos ejemplos, entre muchos otros, son, en Francia, el Sacramentario de Limoges (Bibliothèque Nationale de France, París, 9438, f. 124r); en Inglaterra, los salterios de Shaftesbury (British Library, Londres, [BL], Lansdowne 383, f. 14v) y Winchester (BL, Ms. Nero C IV, f. 28r); en Alemania, el Leccionario del canónigo Marcwardus (Halberstadt, Domschatz, Ms. 132, f. 8v); o en los Países Bajos, la Biblia Stavelot (BL, Add. Ms. 28107, f. 136r).

${ }_{14}$ Fernando Galván consideró que la Maiestas del Panteón pudo inspirar aquella del sacramentario isidoriano en Londres (BL, Add. Ms. 39924, f. 10v). Galván Freile, 1997: 97-99.

15 En torno al marfil isidoriano: Williams, 1993a. Existen multitud de estudios sobre esta pieza, una bibliografía actualizada en: Álvarez da Silva, 2014: 303-310. 
Algo semejante ocurre con la placa de la Traditio Legis que se ha adscrito al taller de eboraria leonés, actualmente en París ${ }^{16}$. En este caso, los vínculos se establecen con la forma doble de la mandorla y, sobre todo, con los símbolos animales cuyas fórmulas se repiten en las tablas de cánones de la Biblia de 1162 y en las pinturas de Roda de Isábena; fundamentalmente el modo en el que se representa la cola del águila con dos líneas que la separan del cuerpo o el escorzo de las cabezas de buey y león ${ }^{17}$. Estos paralelos no implican una influencia directa, pero sí una cultura visual común que circulaba por la colegiata isidoriana desde finales del siglo XI.

Pese a que el análisis comparativo evidencia la relación entre el folio del Arqueológico y el códice bíblico leonés, no existe constancia documental de la procedencia del mismo. Su lugar de origen no se menciona en el escrito de venta que se conserva en el archivo del MAN y no existen referencias al mismo en documento alguno de esta institución o de la Real Colegiata de San Isidoro de León.

El folio fue adquirido por el entonces Museo Nacional de Antigüedades en el año 1874 a Ricardo Velázquez Bosco (1843-1923) ${ }^{18}$. Figura importante en el desarrollo de la colección del organismo, fue fundamental su labor de adquisición y estudio de piezas venidas de la provincia de León, donde se asienta entre 1863 y 1870, colaborando asimismo en la restauración de la catedral ${ }^{19}$. Secretario de la Comisión Provincial de Monumentos de esta región desde 1866 y correspondiente de la Academia de San Fernando, recibió múltiples encargos por parte del museo que se encontraba en pleno proceso de acumulación de obra, llegando a ser nombrado representante del mismo en León en 1868. Su labor se repartió por todo el territorio de la ciudad y alrededores y trabajó, entre otros sitios, en San Isidoro, donando varios vaciados del Panteón, la iglesia y la pila bautismal a la colección madrileña. Asimismo gestionó junto a otros la incautación de objetos de la canónica en 1869, entre los que se encontraban varias arquetas medievales y la cruz de Fernando y Sancha. Por tanto, la misma persona que entregó el folio al MAN había llevado a cabo una extensa labor en la institución isidoriana, de manera que la implicación de Velázquez Bosco apunta a que la Maiestas podría haberse originado en el scriptorium de esta comunidad $^{20}$.

Finalmente cabe indagar en torno a la localización de la pieza dentro del manuscrito. Teniendo en cuenta que, como ya se ha señalado, sus escribas y miniaturistas emularon de manera insistente el modelo del año 960, debía situarse al comienzo del primero de los volúmenes como ocurre en el códice del siglo X donde inicia el libro. El estudio codicológico realizado por Ana Suárez demuestra que es esta una circunstancia posible ya que revela que el primero de los fascículos, hoy desordenado, fue realizado de manera independiente y contaba originalmente con ocho folios de los que faltan el primero y el séptimo (este último estaría entre los ahora enume-

${ }^{16}$ Musée du Louvre, París, n. ${ }^{\circ}$ inventario 0A 5017.

17 Williams, 1993b. El investigador norteamericano ha propuesto que la función original de esta placa era la de cubierta de la Biblia del 960. Esta hipótesis, aunque imposible de contrastar, establecería un interesante punto de contacto entre la pieza y el manuscrito isidoriano. De nuevo, una bibliografía actualizada acerca de este marfil en: Álvarez da Silva, 2014: 271-284.

18 El documento de venta se encuentra en el Archivo del MAN, expediente 1874/32. Contiene un escrito de Francisco Bermúdez de Sotomayor, jefe de la Sección de Numismática y futuro director del museo fechado el 3 de diciembre de 1874 en el que pregunta por la conveniencia de adquirir una serie de objetos. El folio es descrito como "Pintura en pergamino correspondiente a un códice del s. XII; representa a Jesucristo acompañado de los símbolos de los cuatro evangelistas". En este mismo expediente se conserva la confirmación de la compra por sesenta pesetas firmada por Ventura Ruiz Aguilera, director del museo hasta 1872. El texto ha sido transcrito por Franco Mata, 2010: 102.

19 En torno a la adquisición de piezas por el entonces Museo Nacional de Antigüedades: Franco Mata, 1993; 20112013: 79-82. Sobre Velázquez Bosco: Baldellou Santolaria (com.), 1990.

${ }^{20}$ La documentación de las labores de Ricardo Velázquez Bosco en la provincia de León a instancias del museo se recogen en el Archivo del MAN, expedientes 1868-103-B-VIII-1, 1871/25 y el ya mencionado 1874/32. Asimismo, en el Archivo de la Real Colegiata de San Isidoro de León se conserva un documento con el expediente de incautación de las arquetas y el crucifijo bajo la signatura ASIL, Caja 309, Documento 110. Gran parte de estos textos han sido transcritos y estudiados por Franco Mata, 2010: 29-92, quien también ha analizado las múltiples aportaciones de Velázquez Bosco al MAN. 


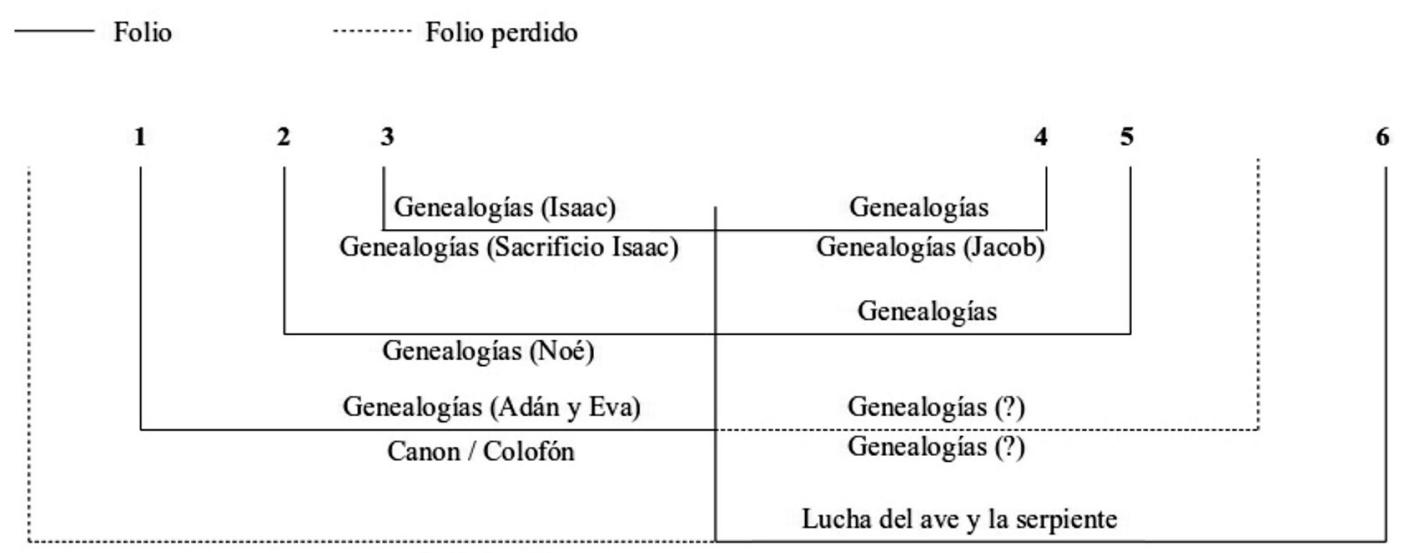

Maiestas (?)

Fig. 8. Reconstrucción hipotética del cuaderno I.1 de la Biblia de 1162 de San Isidoro de León. Basada en Ana Suárez González.

rados como 5 y 6$)^{21}$. Quizá fuese en el proceso de encuadernación que actualmente presentan los volúmenes cuando se dividió este cuaderno, creando como consecuencia un primer fascículo con cinco folios y un talón, e incorporando el último folio de este cuaternión primitivo al binión siguiente (fig. 8). Con ello acaso se resolvía el extravío de los dos folios mencionados que habría ocurrido, por tanto, antes de la encuadernación del siglo XVIII y por ello la foliación, introducida con posterioridad, no cuenta con estos. Atendiendo a esta posibilidad, la Maiestas sería un folio suelto desde al menos la decimoctava centuria, de ahí la falta de datos en torno a su procedencia en su venta al museo en el XIX ${ }^{22}$.

Tanto las circunstancias históricas que rodearon su llegada al Museo Arqueológico Nacional en Madrid, como las evidencias extraídas del análisis codicológico y del estudio comparativo desde el punto de vista iconográfico, estilístico y material, así como su vínculo con las pinturas de Roda de Isábena, demuestran que el folio que ahora se encuentra en el MAN debía ser el frontispicio original de la Biblia de 1162 de la Real Colegiata de San Isidoro de León.

\section{BIBLIOGRAFÍA}

Álvarez da Silva, Noemi (2014): El trabajo del marfil en la España del siglo XI. León: Universidad de León.

Baldellou Santolaria, Miguel Ángel (com.) (1990): Ricardo Velázquez Bosco. Diciembre 1990-Febrero 1991. Salas del Edificio del Antiguo M.E.A.C. Madrid: Ministerio de Cultura.

Castiñeiras González, Manuel A. (1996): El calendario medieval hispano. Textos e imágenes. Siglos XI-XIV. Salamanca: Junta de Castilla y León.

21 Suárez González, 1997: 114 y 255-259.

22 Dado que, como ha mostrado John Williams, este tipo de representaciones se ajustan más a una función como frontispicio de los evangelios que de la Biblia completa, existiría la posibilidad de que la Maiestas hubiese formado parte del otro fascículo independiente del manuscrito, el III.9 (ff. 63-69), que contiene las tablas de cánones y donde falta el último folio. Así, el ejemplar del MAN podría pertenecer a este bifolio mutilado, iniciando el Nuevo Testamento como ocurre en la tercera integrante de esta familia de Biblias hispanas ilustradas, la de San Millán de la Cogolla (Real Academia de la Historia, Madrid, Códices 2-3), realizada hacia 1200. Sin embargo, teniendo en cuenta que en el ejemplar emilianense la Maiestas precede a las tablas de cánones en lugar de situarse tras ellas como ocurriría aquí, y que los códices de 1162 siguen casi al pie de la letra la colocación de las ilustraciones con respecto al modelo del siglo X, es mucho más probable que la Maiestas del MAN hubiese iniciado las Sagradas Escrituras como primer folio del cuaderno inaugural. 
Díaz y Díaz, Manuel Cecilio (1999): "El escriptorio de Valeránica”. En: Martínez, M./Sábugo Pintor, Ángel/del Valle Menéndez, Antonio/Viñayo González, Antonio (eds.): Codex Biblicus Legionensis. Veinte estudios. León: Real Colegiata de San Isidoro/Fundación Hullera Vasco-Leonesa/Universidad de León/Ediciones Lancia, pp. 53-72.

Franco Mata, Ángela (1988): “Arte medieval cristiano leonés en el Museo Arqueológico Nacional”. En: Tierras de León: Revista de la Diputación Provincial, 28, 71, pp. 27-60.

Franco Mata, Ángela (1993): "Las Comisiones Científicas de 1868 a 1875 y las colecciones del Museo Arqueológico Nacional. I. 1868”. En: Boletín de la ANABAD, 43, 3-4, pp. 109-136.

Franco Mata, Ángela (2010): Arte leonés fuera de León (siglos IV-XVI). León: Edilesa.

Franco Mata, Ángela (2011-2013): “Sistemas de acopio de arte medieval en grandes museos". En: Boletín del Museo Arqueológico Nacional, 29-30-31, pp. 65-107.

García Molinos, Elena (2004): "Florencio de Valeránica, calígrafo y notario del siglo X”. En: El reino de León en la Edad Media. XI. León: Caja España de Inversiones/Archivo Histórico Diocesano de León, pp. 241-430.

Galván Freile, Fernando (1997): La decoración de manuscritos en León en torno al año 1200. León: Universidad de León.

Mundó, Anscario M./Sánchez Mariana, Manuel (1976): El Comentario de Beato al Apocalipsis. Catálogo de los Códices. Madrid: Biblioteca Nacional.

Pérez de Urbel, Justo (1975): "El monasterio de Valeránica y su escritorio". En: Homenaje a Don Agustín Millares Carlo. Las Palmas: Confederación Española de Cajas de Ahorros, vol. 2, pp. 71-89.

Shailor, Barbara (1975): The Scriptorium at San Pedro de Berlangas. Cincinnati: University of Cincinnati.

Suárez González, Ana I. (1997): Patrimonio cultural de San Isidoro de León. B. Serie bibliográfica. II. Los códices III.1, III.2, III.3, IV y V (Biblia, Liber Capituli, Misal). León: Universidad de León.

Suárez González, Ana I. (2013): "Una lectura arqueológica de nuestras Biblias medievales (siglos X-XIII in.)". En: Memoria Ecclesiae, 38, pp. 163-214.

Williams, John (1962): The Illustrations of the León Bible of the Year 960 - An Iconographic Analysis. Ann Arbor: University of Michigan.

Williams, John (1970): "A Contribution to the History of the Castilian Monastery of Valeranica and the Scribe Florentius". En: Madrider Mitteilungen, 11, pp. 231-248.

Williams, John (1993a): "Reliquary". En: The Art of Medieval Spain. A. D. 500-1200. The Metropolitan Museum of Art. New York: Metropolitan Museum of Art, p. 247.

Williams, John (1993b): “Christ in Majesty with saints Peter and Paul”. En: The Art of Medieval Spain. A. D. 500-1200. The Metropolitan Museum of Art. New York: Metropolitan Museum of Art, pp. 246-247.

Yarza Luaces, Joaquín (1985): “La peregrinación a Santiago y la pintura y miniatura románicas”. En: Compostellanum, 30, pp. 369-393.

Yarza Luaces, Joaquín (1990): “La Miniatura Románica en España. Estado de la Cuestión”. En: Anuario del Departamento de Historia y Teoría del Arte (UAM), 2, pp. 9-26.

Yarza Luaces, Joaquín (1994): "Miniatura". En: de la Plaza Santiago, Francisco Javier/Marchán Fiz, Simón (dirs.): Historia del Arte de Castilla y León. Tomo II. Arte Románico. Valladolid: Ámbito Ediciones, 1994, pp. 263-292.

Fecha de recepción: 11-XI-2015

Fecha de aceptación: 22-I-2016 